\title{
LOS VALLES DE ALCOI DURANTE LA ROMANIZACIÓN: ANÁLISIS SIG DE LA ESTRUCTURA TERRITORIAL
}

\author{
IGNACIO GRAU MIRA \\ Universidad de Alicante*
}

\begin{abstract}
En el siguiente trabajo se analiza la estructura territorial de los valles de Alcoi (Alicante) durante la época de la romanización, entre los ss. II y l a.C. Para nuestro propósito emplearemos los Sistemas de Información Geográfica (SIG), en especial las técnicas conocidas como Análisis de Visibilidad Acumulada o Cumulative Viewshed Analysis. El estudio del paisaje muestra una aparente continuidad de la estructura territorial, marcada por la pervivencia del oppidum ibérico, pero en esencia el modeio ibérico se encuentra en descomposición y no servirá de base al paisaje surgido de la romanización.
\end{abstract}

In this paper we analyse the territory of the valley of Alcoi (Alicante) during Romanization, between the 2nd and 1st centuries BC. We use Geographic Information Systems (GIS), particularly Cumulative Viewshed Analysis. The study of the landscape shows an apparent continuity of the Iberian territorial structure which is marked by the survival of the Iberian oppidum, although the Iberian model was in decline and did not act as the framework for the new Roman landscapes.

\section{INTRODUCCIÓN}

La investigación tradicional venía concibiendo la romanización como un proceso lineal conducente a la implantación de los modelos romanos en sustitución de las estructuras ibéricas. Esta dinámica se observaba desde un punto de vista de predominio romano que acababa imponiendo los patrones culturales, políticos y sociales sobre la disuelta sociedad ibérica. Las variaciones que podían observarse desde esta perspectiva, principalmente en la adopción de la nueva cultura material, respondían a la gradación temporal y a la velocidad de las transformaciones en una amplia y variada área geográfica. Esta visión tradicional ha ido cambiando con el transcurso de la investigación durante los últimos años y en la actualidad el proceso de romanización contempla una multitud de aspectos y observa las transformaciones desde perspectivas amplias y complejas ${ }^{1}$.

Uno de los aspectos más importantes es la incorporación al discurso principal del papel activo jugado por las sociedades nativas que se reorganizan y se redefinen en las circunstancias propias de su contacto con Roma (Keay,
$2001,128-130$ ). Dichos cambios quedarían reflejados en la organización del poblamiento y del territorio del periodo y en ese sentido nos parece de interés analizar el paisaje ibérico durante el periodo ibérico final, en los siglos III a.C. Durante esa fase se observan variadas transformaciones que difícilmente pueden englobarse en una misma dinámica. Estas distintas respuestas nativas se producen en el in-

\footnotetext{
Este trabajo se ha realizado en el marco de una beca postdoctoral de la Secretaría de Estado de Educación y Universidades desarrollada en el Department of Archaeology de la University of Southampton (U.K.) y se integra en el proyecto BHA 2002-02028 del MCYT.

1 Son muy numerosos los trabajos sobre la romanización aparecidos en los últimos años, entre ellos queremos destacar por su carácter de compendio Abad, L. (Ed.) 2003: De Iberia in Hispaniam: la adaptación de las sociedades ibéricas a los modelos romanos, Madrid-Alicante; Blázquez J. M. y Alvar, J. (Eds.) 1996: La romanización en occidente. Madrid; Keay, S. y Terrenato, N. (Eds.) 2001: Italy and the West. Comparative issues in Romanization. Oxford; Mayer, M., Nolla, J M. y Pardo, J. (Eds.) 1998: De les estructures indigenes a l'organització provincial romana de la Hispania Citerior. Barcelona, o El dossier monográfico La formación d'una societat provincial. La component ibèrica a les fundacions romanes del Nord-Est de la Hispania Citerior publicado en la revista Empúries, 52. 2000.
} 
terior de una determinada región, de forma que áreas vecinas muestran procesos diferentes $e$ incluso de naturaleza contraria, pues mientras un valle sufre destrucciones y abandonos, en la zona contigua el poblamiento se mantiene básicamente estable o se incrementa. Esta multiplicidad de procesos requiere de un análisis detallado del territorio a escala reducida que permita identificar y valorar los cambios e insertarlos en la tendencia general de integración en las nuevas estructuras del mundo romano.

En las siguientes páginas nos proponemos realizar un análisis comparativo de la estructura territorial de los periodos consecutivos de fines de época plena: s. III a.C. y época ibérica final en los SS. II-I a.C. Ello nos permitirá observar con detalle las similitudes y diferencias entre el paisaje ibérico clásico y aquel que empezó a configurarse con el primer contacto con Roma. A nuestro parecer, en los primeros momentos de la dominación romana del área oriental de la Península Ibérica debió existir un elevado nivel de autonomía de las poblaciones nativas que debió reflejarse en la forma de organizar los paisajes. Sin embargo, los cambios impuestos por las nuevas condiciones políticas y económicas debieron incidir en la posterior construcción del paisaje romano que en el País Valenciano se produjo principalmente a partir de época de Augusto (Tarradell, 1988, 129).

Un segundo objetivo de este trabajo es de carácter metodológico, pues nos proponemos emplear los Sistemas de Información Geográfica (SIG), en particular las técnicas de Cumulative Viewshed Analysis o Análisis de Visibilidad Acumulada, describiendo detalladamente esta técnica y su aplicación para el estudio del territorio antiguo. De esta forma pretendemos incidir en la aplicación de la tecnología SIG en los estudios de paisaje arqueológico cuyo uso, aunque creciente, aun es significativamente reducido en el ámbito de la investigación española.

\subsection{Los valles de Alcoi en época ibérica y romana: un conocimiento desigual}

El área de estudio es el valle del río de Alcoi o Serpis, también conocida bajo la denominación de las comarcas de l'Alcoià y El Comtat, en el norte de la provincia de Alicante (Fig. 1). Se trata de una unidad de paisaje claramente definida en sus rasgos geográficos por su configuración de valle fluvial orlado por una

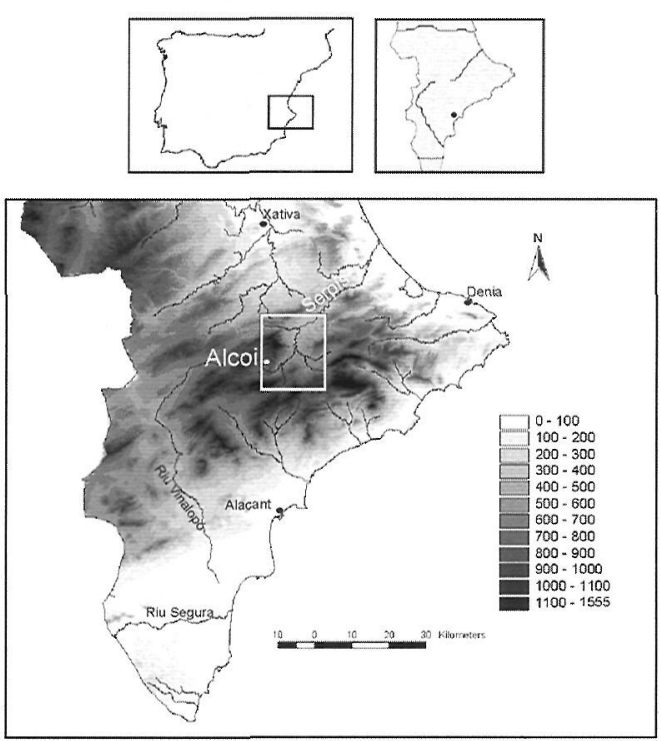

Figura 1: Localización de los Valles de Alcoi.

serie de elevadas sierras que lo delimitan. La larga tradición de investigación arqueológica y el desarrollo de recientes programas de prospecciones sistemáticas han permitido un satisfactorio conocimiento arqueológico que ha servido de armazón para los recientes estudios sobre el paisaje y poblamiento antiguo (Visedo, 1959; Llobregat, 1972; Abad, 1992; Martí y Mata, 1992; Espí, 2001; Grau Mira, 2002a). Estos trabajos han puesto de manifiesto la existencia de una compleja estructura territorial de época ibérica organizada por una red de asentamientos con variadas funciones e importancia.

Frente a un amplio conocimiento del paisaje ibérico, los restos romanos han pasado prácticamente desapercibidos y parcialmente inéditos. No es que sean pocos los sitios detectados, pero ocurre que las únicas evidencias de poblamiento son escasas dispersiones cerámicas entre las tierras de cultivo, raramente asociadas a estructuras de hábitat. El registro arqueológico nos permiten reconocer un poblamiento agrícola disperso de escasa envergadura (Abad, 1984; Grau Mira, 1996a y 1996b; 2001) y algunas evidencias funerarias (González Villaescusa, 2001). No se han detectado vestigios de obras públicas, caminos o parcelarios agrícolas; tampoco se han atestiguado alfares o centros de producción cerámica local. Las evidencias epigráficas y numismáticas se reducen a algunas monedas, principalmente bajoimperiales, depositadas como ofrendas en el santuario de La Serreta (Visedo, 1923; Abad, 1984) y una sola inscrip- 
ción funeraria extremadamente sencilla (Grau y Moltó, 1996).

Esta parquedad y sencillez de los restos romanos conocidos ha sustentado las teorías de un escaso desarrollo cultural que convirtió la zona en un área con fuerte permanencia de rasgos indígenas (Llobregat, 1984) y que debió permanecer al margen de las principales adaptaciones causadas por el proceso de romanización. La continuidad se puede observar claramente en la cultura material de la zona, caracterizada por la pervivencia de elementos de factura típicamente ibérica. Buena parte de estas perduraciones se deberian a un cierto aislamiento geográfico de la comarca, enclavada en un área montañosa con dificultades de comunicación y en la periferia de las ciudades que articularon el sur del Conventus Cartaginensis (Grau Mira, 2000). Estas condiciones provocarian el mantenimiento de un foco de población poco expuesto a los cambios y de difícil integración en los modelos urbanos romanos.

No cabe duda de que el periodo romano supuso una destacada reorganización de los polos de poblamiento y las estructuras territoriales en la región meridional del País Valenciano y como consecuencia de ello la comarca alcoyana vio declinar su poblamiento y papel en la articulación geográfica regional frente a unas comarcas vecinas que se desarrollaron de forma significativa (Abad, 1985). Lo que no se conoce de forma precisa es cómo se produjo este proceso a escala local, es decir, cómo las comunidades ibéricas del valle de Alcoi se transformaron durante la fase ibérica final. A priori, la continuidad de la mayor parte de los oppida ibéricos de la zona permitiría proponer una continuidad de las estructuras politicas y socioeconómicas representadas por este modelo de ocupación del territorio. Nuestro propósito es precisamente analizar la evolución de la estructura territorial a escala local, tomando como elemento de análisis la evolución de las unidades básicas del territorio formadas por el oppidum y el sistema de poblamiento de su entorno inmediato. Nos concentraremos en el análisis de tres tipos de variables complementarias: el patrón de asentamiento, la distribución del poblamiento y el análisis de la estructura visual. A través de ellos nos introduciremos en la complejidad de los fenómenos de transformación del paisaje durante la romanización.

\subsection{Estructura del territorio, visibilidad y SIG}

El análisis de los patrones de asentamiento y la relación espacial entre yacimientos han sido pilares en los que se han basado los estudios clásicos de poblamiento y territorio desde que se fijaron las bases de la Arqueología Espacial (Hodder y Orton, 1976; Clarke, 1977). Estas investigaciones están basadas en los principios de la Geografía Locacional (Haggett, 1965) que asumen la posibilidad de analizar una trama de poblamiento mediante métodos cuantitativos, la realización de análisis formales o estadísticos y el estudio de sus estructuras para reconocer las formas de organización social y económica que subyacen a los patrones observados. La evolución de los estudios clásicos de Arqueología Espacial, desarrollados en nuestro país a partir de los años 80 , y la incorporación de nuevos planteamientos teóricos y metodológicos, dio lugar a una disciplina plural que se conoce como Arqueología del Paisaje y que contempla una gran variedad de enfoques y tendencias ${ }^{2}$.

Un elemento que ha adquirido importancia creciente en los actuales estudios del territorio y paisaje es el análisis de la visibilidad. Las relaciones de visibilidad, es decir, la capacidad de percibir visualmente el entorno desde un determinado asentamiento o la forma en que este es percibido desde sus proximidades, es un elemento de gran valor para la comprensión de los territorios antiguos. Tradicionalmente se ha venido valorando el campo de visión desde los asentamientos, pero no ha sido hasta fechas recientes en que los aspectos teóricos y metodológicos relacionados con la visibilidad han sido descritos en detalle en las propuestas y los procedimientos para el análisis de paisajes arqueológicos (Burillo et al., 1993; Criado Boado, 1993; 1999, 26-34).

Por lo que respecta a los estudios de territorio en época ibérica, ha sido frecuente la investigación de la capacidad de control visual de los asentamientos principales del sistema de poblamiento, los oppida, y otros enclaves que dominan visualmente el paisaje circundante en función de su emplazamiento en altura y en localizaciones destacadas de su entorno. Con frecuencia, la capacidad visual es objeto úni-

2 Remitimos al volumen Arqueología Espacial XIX-XX. Arqueologia del Paisaje. Teruel, 1998, especialmente las contribuciones de los editores, para reconocer la variedad de enfoques que presenta en la actualidad esta disciplina. 
camente de algunas menciones y comentarios fruto de un conocimiento del terreno avalado por trabajos de campo. En otras ocasiones se señala la intervisibilidad entre asentamientos que establecen redes de comunicación visual y en los estudios más detallados se señalan la cuencas visuales de dominio efectivo desde un determinado asentamiento.

El elemento visual se asocia principalmente al factor estratégico y defensivo inherente a los núcleos de poder ibéricos (Ruiz y Molinos, 1993, fig. 93) y de su análisis se derivan interesantes observaciones sobre la estructura del territorio. Por una parte la observación detallada de la cuenca de dominio visual del oppidum permite reconocer la situación y extensión de su dominio, valorando su valor simbólico como punto de referencia en el paisaje (Lock y Harris, 1996), o su importancia como referente político y refugio de las poblaciones rurales en caso de necesidad (Grau Mira, 2002b, 45-46).

Por su parte, el estudio de la unión de cuencas visuales individuales permite reconocer las agregaciones de asentamientos que pueden constituir unidades de carácter político (Moratalla, e. p.), toda vez que la unión visual permite reconocer la articulación territorial de un conjunto de asentamientos. La exploración de la intervisibilidad también ha servido para plantear la existencia de sistemas defensivos de frontera asociadas a proyectos políticos, como es el caso de la atalayas edetanas (Bonet y Mata, 2002, fig. 204), o a la creación de tramas de comunicación intervisual mutua, como en el caso de los oppida contestanos (Grau Mira, 2002a, 209-214).

Todos estas investigaciones tienen como denominador común que se basan en un valor binario sencillo que atiende únicamente las áreas de visibilidad-invisibilidad desde un determinado punto de observación. Además, suelen centrar su atención en la visibilidad desde los núcleos de altura, generalmente los oppida dominantes, cuya capacidad visual se interpreta en función de la importancia estratégica de observar a los vecinos y controlar las posibles incursiones. No ha sido hasta tiempos recientes que de la mano de las posibilidades que ofrecen los Sistemas de Información Geográfica (SIG) se han empezado a desarrollar modelos teóricos y metodológicos que permiten el análisis de la visibilidad desde enfoques más variados y complejos.

En el campo de los estudios de SIG recientemente ha sido introducido el concepto de
Visualscape ${ }^{3}$ definido como la representación espacial de cualquier propiedad visual generada o asociada a la configuración espacial (Llobera, 2003, 30). Entre las exploraciones de las propiedades visuales que mayor acogida han tenido en las aplicaciones SIG en arqueología cabría destacar el Cumulative Viewshed Analysis o 'análisis de visibilidad acumulada' (Wheatley, 1995), técnica que permite investigar el patrón de intervisibilidad en un conjunto de asentamientos en relación con las condiciones del paisaje natural en el que se insertan. El 'análisis de visibilidad acumulada' se basa en la suma de los campos de visibilidad individuales de cada uno de los asentamientos o puntos elegidos del paisaje. El resultado muestra una superficie de terreno en la que se señala el número de asentamientos que pueden observar cada porción del terreno y esta superficie puede ser objeto de tratamiento estadistico o comparativo (Wheatley y Gillings, 2002, 206).

Este tipo de exploraciones es muy poco frecuente en el ámbito de la arqueología española, como lo son aun en general las aplicaciones de los SIG al estudio del paisaje más allá de la gestión de bases de datos y las presentaciones cartográficas ${ }^{4}$. Entre las escasa muestras de estudios de visibilidad-SIG al territorio protohistórico peninsular debemos citar el análisis comparativo de la visibilidad computerizada y la real en el valle del Genil de M. Zamora (2002) o el análisis de la visibilidad en el territorio de Carmona en época turdetana y romana (Keay et al., 2001). Dicho trabajo aborda el estudio de la visibilidad a escala local en el entorno de la ciudad romana de Salpensa, investigando la relación entre el poblamiento romano y su antecedente prerromano empleando el 'análisis de visibilidad acumulada' (Keay et al., 2001, 408).

Siguiendo planteamientos semejantes a los practicados por Keay y colegas, en el presente trabajo vamos a analizar la organización

\footnotetext{
3 El término Visualscape es una fusión de las palabras inglesas visual y landscape que podrian traducirse de forma aproximada como paisaje visual.

${ }^{4}$ Véanse las obras de Baena, J., Blasco, C. y Quesada, F. (Eds.), 1997: Los S.I.G y el análisis espacial en Arqueologia. Madrid; y Sande Lemos, F., Baena, J., Dantas Giestas, C. y Rocha, G. (Coords.), 2000: Sistemas de Informação Arqueológica. SIG's aplicados à Arqueologia da Península Ibérica. Actas do $3^{\circ}$ Congresso de Arqueologia Peninsular. vol. $X$. Porto, donde se compendian buena parte de los trabajos SIG realizados en la Península Ibérica.
} 
territorial a partir de los patrones de visibilidad del conjunto de asentamientos. Nuestro interés es examinar las estructuras visuales creadas por los núcleos de época ibérica plena y final y observar la existencia de posibles variaciones durante el periodo de la romanización. El valor de esta técnica reside en que nos permite aproximarnos a la estructura visual de todo el conjunto de asentamientos y no a la creada por el núcleo principal del territorio, como suele ocurrir con el análisis de la cuenca visual sencilla. De esta forma, los cambios en la distribución del poblamiento que se producen entre el periodo ibérico pleno y final tendrán su correlato en transformaciones de sus respectivas estructuras visuales.

Por lo general, los resultados de los cálculos de visibilidad acumulada suelen ser procesados estadísticamente para relacionar las características de la visibilidad de los asentamientos con relación a la que ofrece el entorno natural en el que se insertan o el grado de relevancia del patrón mostrado por distintos conjuntos de yacimientos (Wheatley, 1995; 1996). En nuestro caso, nos proponemos realizar un estudio comparativo de las estructuras visuales generadas por los conjuntos de asentamientos de una misma zona en periodos consecutivos. Mediante esta procedimiento de cotejo trataremos de contrastar las hipótesis sobre la transformación territorial durante el periodo ibérico tardío.

\section{LA EVOLUCIÓN DEL PATRÓN DE ASEN- TAMIENTO}

A fines de la época clásica, en la segunda mitad del s. III a.C., el poblamiento de la comarca alcoyana se encontraba organizado a partir de un patrón de asentamiento jerarquizado en cuya cúspide se encuentra la ciudad de La Serreta. Se constituyó de esta manera un territorio político articulado en torno a la cuenca hidrográfica del río de Alcoi, semejante al modelo del pago definido en el Alto Guadalquivir (Ruiz et al., 2001). Este pago aglutinaba diversas unidades territoriales básicas constituidas por los diferentes valles de la comarca. En cada una de estas unidades de paisaje el control y explotación del territorio era ejercido por un oppidum secundario.

Desde un punto de vista morfológico, el oppidum del área contestana se define como un enclave de altura que alcanza un tamaño aproximado de dos hectáreas, está protegido por defensas naturales y obras de fortificación y cuenta con una trama urbanística densa y ordenada. El oppidum concentra la mayor parte de la población del entorno y reúne una variada gama de funciones de carácter estratégico, económico y político. Es la residencia de las elites rectoras de la sociedad que dirigen la producción agropecuaria y la redistribución de los bienes de prestigio (Grau Mira, 2002a, 250254).

Junto al oppidum encontramos una serie de núcleos de carácter rural, caracterizados por su carácter abierto y su localización en las tierras bajas, adyacentes a los campos de cultivo. En función de la extensión de estos núcleos rurales, fijada por la dispersión superficial de restos cerámicos, se han establecido dos tipos de asentamientos: hábitats de tamaño medio, en torno a la media hectárea, denominados aldeas, y núcleos de tamaño reducido, denominados caseríos, cuya superficie ronda en torno a los $500 \mathrm{~m}^{2}$ (Grau Mira, 2002a, 119-121). Las aldeas y los caseríos debieron ser las residencias de la población campesina que se establecería junto a sus campos de cultivo dedicados a las labores agrícolas. En función del tamaño del hábitat podemos suponer una varie-

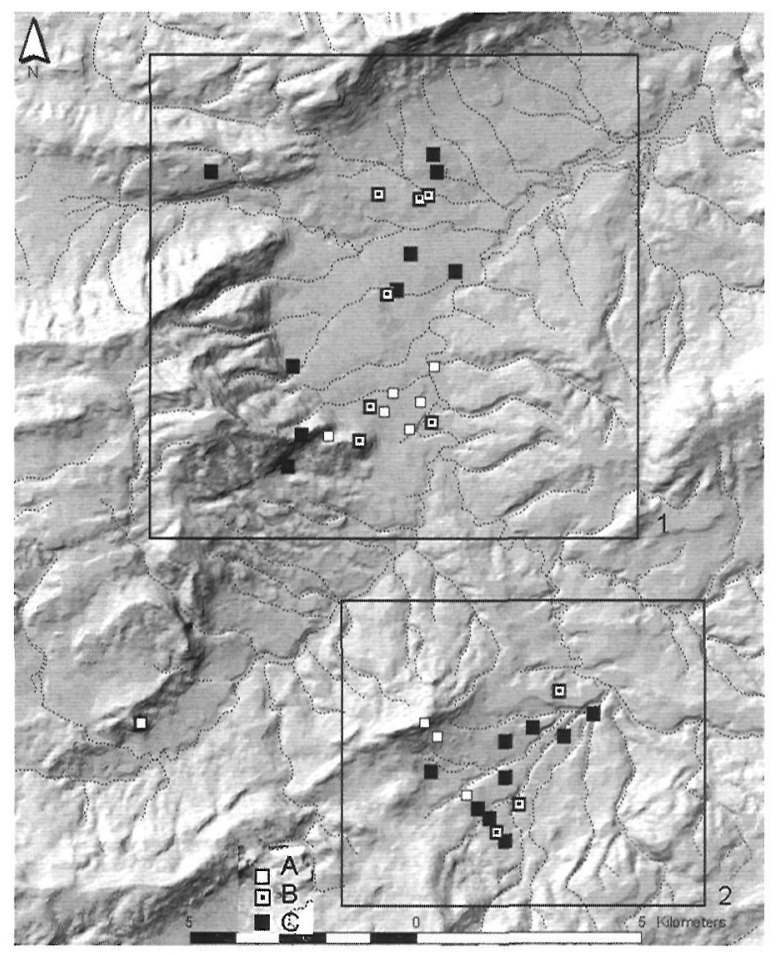

Figura 2: Localización de las áreas de estudio en los valles de Alcoi. 1: Territorio de Cocentaina. 2. Territorio de La Serreta. A: Asentamientos de época ibérica plena, s. III a.C. $B$ : Asentamientos de época ibérica plena y final. $C$ : Asentamientos de época final. 

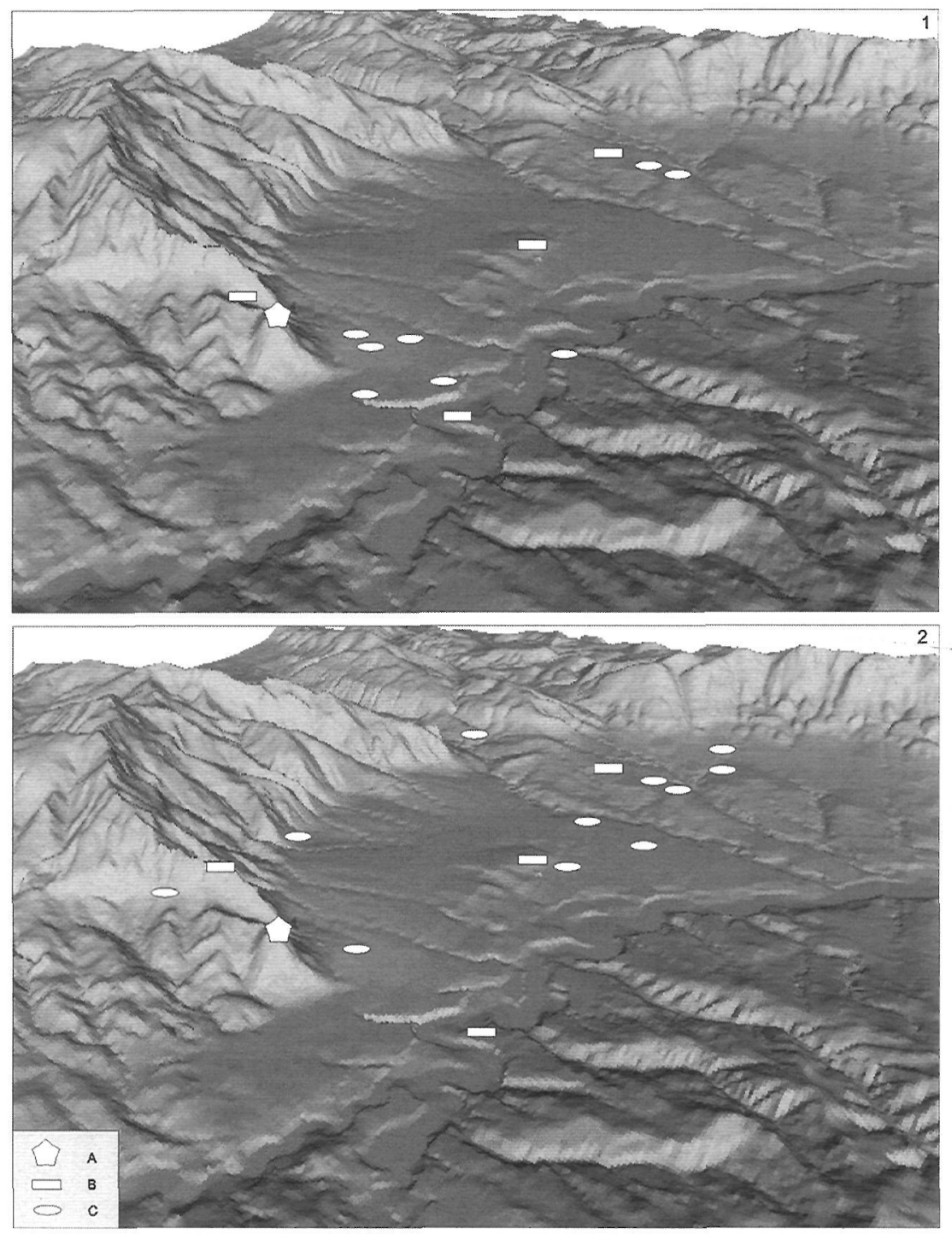

Figura 3: Modelo digital del terreno y el poblamiento del territorio de El Castell de Cocentaina. 1. Época Ibérica plena, s. III a.C. 2: Época ibérica final. A: Oppidum. B: Aldeas. C: Caseríos.

dad de establecimientos rurales que irian desde el pequeño núcleo de carácter familiar hasta las pequeñas concentraciones rurales donde es posible que convivieran los campesinos y los grupos propietarios de la tierra, según se desprende de la existencia de monumentos funerarios junto a alguna de las aldeas. De esta forma, las aldeas podrían tratarse de posesiones territoriales señoriales semejantes al caserío edetano del Castellet Bernabé (Guérin, 1999; 2003).

Este esquema básico de núcleo concentrado y un variado poblamiento rural se repite en la mayor parte de los valles y otros espacios que configuran unidades independientes del paisaje contestano y es la célula básica de ordenación del poblamiento de época clásica. En el siguiente estudio concentraremos nues- tra atención en dos de estas unidades paisajísticas que representan dos modelos distintos de evolución del poblamiento. El primero de ellos es el área del Comtat, en el Valle Medio del Serpis, controlado por el oppidum del Castell de Cocentaina (Fig. 2, 1). La segunda zona de análisis es el valle del Frainós que constituye el espacio de control directo de La Serreta (Fig. 2, 2). Ya ha quedado dicho que esta ciudad era la capital de toda la comarca pero al mismo tiempo organizaba y explotaba directamente el espacio de su valle adyacente.

Durante el s. III a.C. en El Comtat encontramos el Castell de Cocentaina y un denso poblamiento en Ilano compuesto por cuatro aldeas: Els Ametllers, El Terratge, L'Arpella y L'Alt del Punxó y ocho caseríos: C. Dénia, C. Industria, Les Jovades, Fraga, L'Alcavonet, EI 


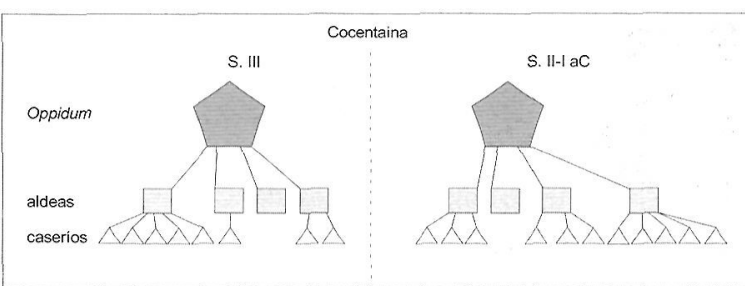

Figura 4: Esquema del patrón de asentamiento en el territorio de Cocentaina.

Sompo, L'Almoroig y Cementeri de Cela. (Grau Mira, 2002a, 128) (Fig. 3, 1). Estos poblados componen un patrón de asentamiento de clara estructura jerárquica (Fig. 4) encargada de la gestión directa del valle y sobre la que se impondría La Serreta como la ciudad rectora de toda la comarca.

El periodo ibérico tardío en este valle muestra un considerable grado de continuidad si atendemos a la pervivencia de los poblados y el patrón de asentamiento. El Castell de Cocentaina perdura durante los siglos II-I a.C. hasta los inicios de época imperial. Junto al poblado principal aparecen representados los mismos tipos de asentamientos rurales del periodo precedente y en un número semejante. Encontramos cuatro aldeas: El Pic Negre, El Terratge, L'Arpella y L'Alt del Punxó, de las cuales tres perduran desde el periodo anterior. En el nivel básico del poblamiento encontramos nueve caseríos: El Mas de la Penya, C. Dénia, La Querola, Marges Alts, La Fàbrica d'Abdón, Reial Franc, El Cementeri de Cela, L'Almoroig, El Quint, El Mas d'Alfafar y El Riu d'Agres (Grau Mira, 2002a, 129-130). En este nivel es donde se producen los principales cambios, pues únicamente dos de los anteriores núcleos perduran, al tiempo que se produce una amplia redistribución de la ocupación rural (Fig. $3,2)$.

El modelo de Cocentaina representa la continuidad del patrón de asentamiento entre la época plena, s. III, y la época final, ss. II-I a.C. (Fig. 4). Los cambios se reducen a una redistribución de la ocupación campesina dispersa, mientras que los núcleos concentrados de mediano y gran tamaño se caracterizan por su persistencia. De ello podría deducirse una estabilidad de las estructuras económicas y políticas representadas por el oppidum ibérico y sus núcleos dependientes de mayor tamaño.

A diferencia del modelo de Cocentaina, el patrón del territorio de La Serreta mostraría las principales transformaciones en la estructura del poblamiento. El área de control directo de La Serreta durante el s. III a.C. está ocupa- do por dos aldeas: La Condomina y El Bancal de Satorre y tres caseríos: La Torreta, L' Altet del Vell (Grau Mira, 2002a, 128) y Les Vaquerises (Espí, 2001, 88) (Fig. 5, 1).

A fines del s. III o inicios del s. II a.C. se desocupa la ciudad de La Serreta. Las evidencias arqueológicas señalan un abandono repentino que se ha vinculado al impacto producido por el inicio del control romano de la región, bien en el contexto de la Segunda Guerra Púnica, bien por las acciones de control de inicios del s. II a.C. (Llobregat et al., 1995; Olcina et al., 1998; 2000; Grau Mira, 2002a).

De forma paralela al abandono del enclave urbano se observa una intensificación de la ocupación rural, en lo que puede interpretarse como un traslado de la población de La Serreta hacia el llano circundante. Encontramos una densa red de núcleos agrícolas constituida por una aldea, La Condomina, y diez caseríos: El Mas del Pla, L'Altet del Vell, El Carrascalet, La Capella, Les Puntes 3, EI Mas Blanc, El Mas de Cantó, Els Horts, El Mas Gran de Pellicer y La Torreta (Grau Mira, 2002a, 129-130; Espí, 2001, 103) (Fig. 5, 2).

A consecuencia del abandono de la Serreta sin que fuera reemplazado por un núcleo rector de semejantes características, el territorio del Frainós careció de una estructura jerárquica durante los siglos de la época ibérica final $^{5}$ (Fig. 6). Por consiguiente, este modelo constituiría el ejemplo de las transformaciones sufridas por el territorio ibérico en el primer contacto con Roma, que desmantelaría las estructuras de poder establecidas en época precedente. Cabe indicar que posiblemente la desocupación de la Serreta debió ser fruto de una acción destinada a eliminar la ciudad rectora del amplio territorio de la comarca alcoyana, de forma que descapitalizando el territorio se lograba su subyugación y se evitaba la existencia de un posible foco de resistencia, pero tuvo como efecto secundario la desarticulación del territorio inmediato del Frainós.

Los modelos de Cocentaina y Frainós representan, a grandes rasgos, la continuidad y el cambio en el poblamiento ibérico de los Valles de Alcoi. Cabe indicar que la mayor parte de los valles de la comarca mostrarían una evolución semejante a la observada en Cocentaina, de lo que se podría deducir una

\footnotetext{
${ }^{5}$ En el sector oriental de este valle encontramos el oppidum del Castell de Penàguila, pero su relativa lejanía no permite suponer una relación directa con la trama de poblamiento rural aquí descrita.
} 

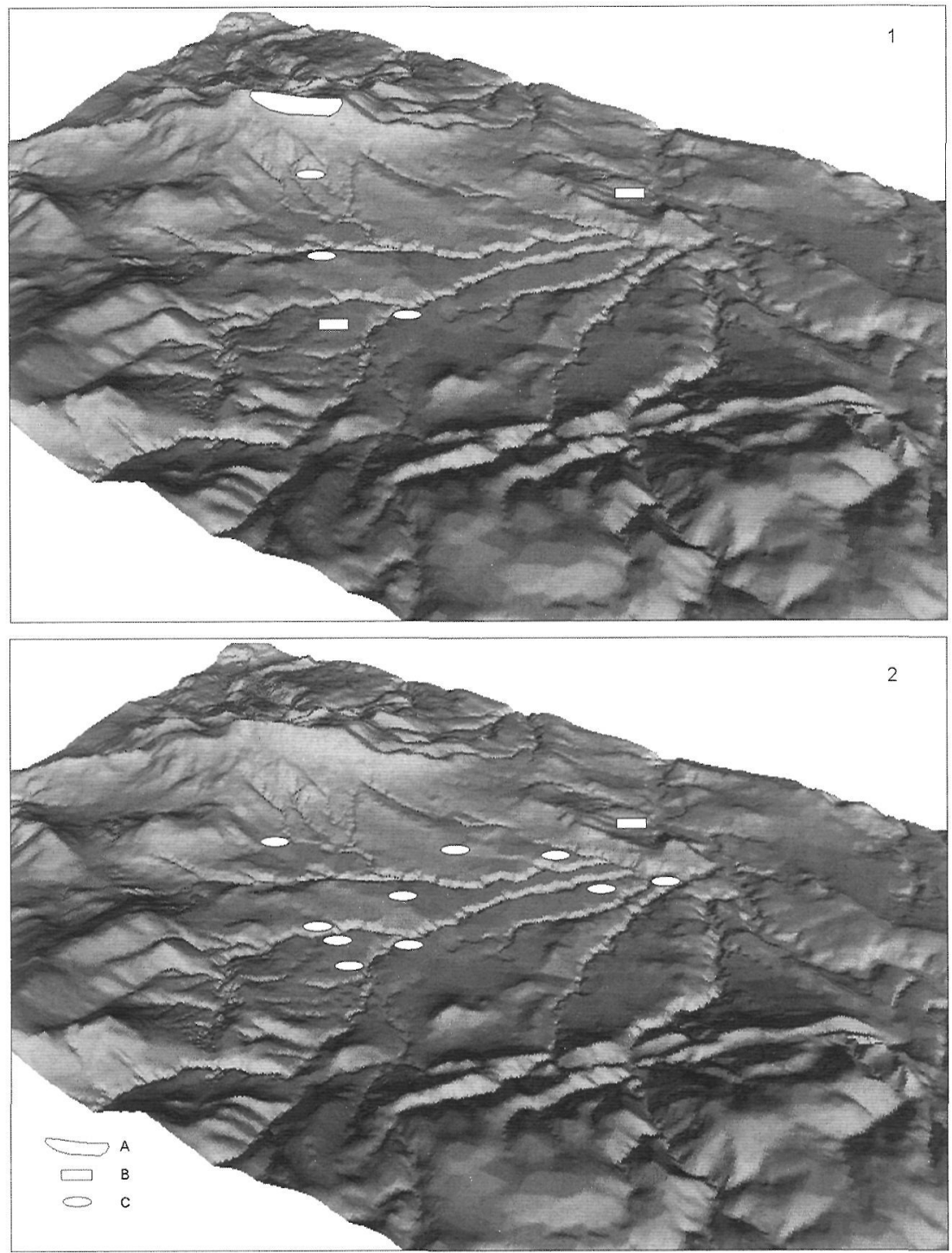

Figura 5: Modelo digital del terreno y el poblamiento del territorio de la Serreta en el valle de Frainós. 1. Época Ibérica plena, s. III a.C. 2: Época ibérica final. A: Oppidum. B: Aldeas. C: Caseríos.

pauta general de continuidad comarcal en el patrón de asentamiento durante la época ibérica final (Grau Mira, 2002a, 129-130). No obstante, un análisis con detenimiento en la estructura territorial ofrece diferentes perspectivas en la observación de la dinámica territorial del periodo.

\section{LA DISTRIBUCIÓN DEL POBLAMIENTO Y LA ESTRUCTURA TERRITORIAL}

Hasta el momento nos hemos ocupado exclusivamente de los cambios observados en el patrón de asentamiento, en lo que podíamos denominar las relaciones jerárquicas verticales en la trama del poblamiento. Como síntesis de esta primera observación, señalábamos la existencia de un modelo, representado por el de El Castell de Cocentaina y su territorio, que mostraba la continuidad y la perduración de las estructuras jerárquicas propias del poder ibérico, especialmente evidente en la pervivencia del oppidum como centro político rector del territorio. Ahora bien, si estas pautas nos permi-

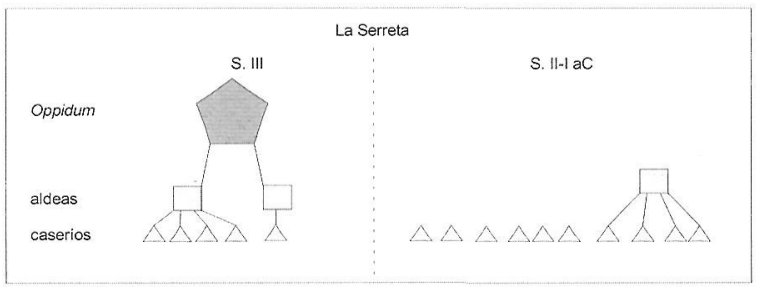

Figura 6: Esquema del patrón de asentamiento en el territorio de la Serreta. 


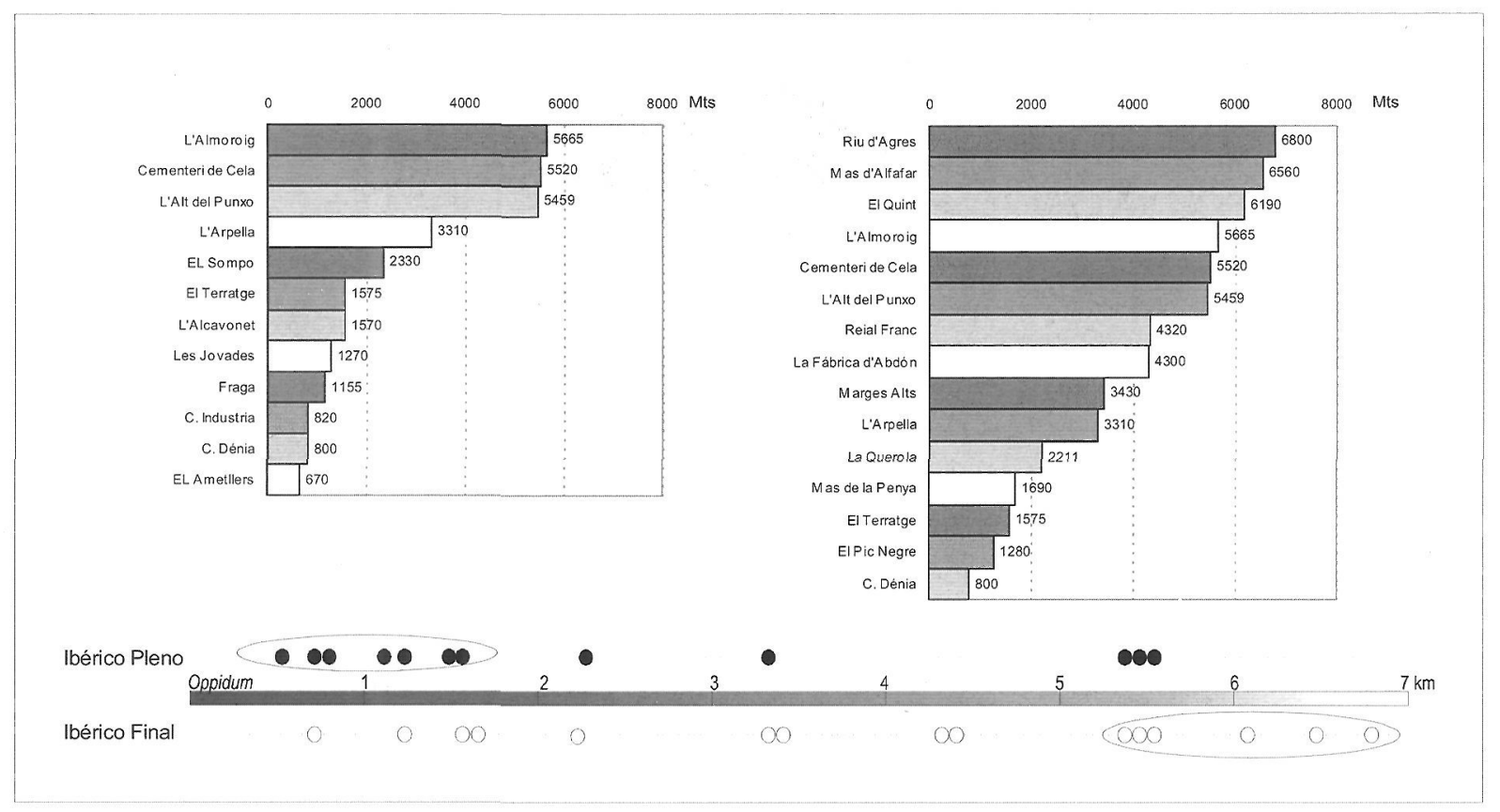

Figura 7: Distribución de los núcleos rurales en el territorio de Cocentaina analizada a partir de la distancia entre el oppidum y los asentamientos dependientes. Obsérvese el alejamiento durante época ibérica final.

ten postular un intenso grado de continuidad, los cambios observados en la distribución del poblamiento muestran una realidad bien diferente. A continuación nos centraremos en las relaciones horizontales o de situación de los núcleos en el área de control político del oppidum de Cocentaina, atendiendo a las pautas de localización que permiten la interacción social entre el poblado rector y los asentamientos subordinados.

Durante el s. III a.C. se observa una concentración de poblados en las proximidades del oppidum de Cocentaina, donde se localizan ocho de los doce asentamientos dependientes, es decir, dos tercios del total se sitúan a menos de 1'6 km de distancia en línea de aire (Fig. 7). Esta agrupación en las cercanías del poblado principal debe relacionarse con las funciones económicas y las necesidades sociales y políticas propias de las estructuras de poder ibéricas. El oppidum es el lugar de residencia de las elites y centro de decisión política, proporciona refugio a las comunidades campesinas del valle, ofrece servicios, es el lugar de concentración de la producción y sede de los intercambios. Ruiz se ha referido a esta tendencia de los clientes a estar alrededor del personaje de prestigio relacionándola con el ambactus, fenómeno común a otras comunidades de la edad del hierro europea (Ruiz, $1998,298)$. Esta prioridad social produciría la existencia de una focalización del poblamiento en torno al enclave principal, plasmando el principio de que la intensidad del poder político está en proporción directa a la proximidad de su fuente (Cherry, 1987, 160-166).

Los restantes núcleos rurales se localizan a mayor distancia, entre 2,3 y $5,7 \mathrm{~km}$ aproximadamente y destaca la existencia de una agrupación propia a una distancia de 5,5 $\mathrm{km}$ que forma un foco claramente individualizado. Este conjunto se ordena en torno a la aldea de L'Alt del Punxó, un núcleo de carácter concentrado que parece desempeñar un papel importante en la organización del sector septentrional de la comarca, especialmente a nivel estratégico como punto de conexión visual de los oppida de la región (Grau Mira, 2002a, 199). La primacía de este núcleo quedaría avalada en la larga secuencia temporal de su ocupación y por sus rasgos morfológicos (Espí, 2001, 107).

La distribución del poblamiento en el periodo final muestra unos rasgos muy distintos en los que destaca la desaparición de la densidad que existía junto al poblado rector. Pese a la existencia de cuatro núcleos en el entorno del oppidum, a distancias inferiores a $1,7 \mathrm{~km}$, la concentración principal se observa en el área más alejada del poblado de altura, donde seis asentamientos se sitúan entre 5,4 y 6,8 km. Este conjunto se organiza de nuevo concentrado en torno a la aldea de L'Alt del Punxó que parece consolidar su función en la ordenación del sec- 
tor septentrional, especialmente en las productivas tierras de cultivo de La Plana de Muro (Grau Mira, 2002a, 130).

La segunda característica es la mayor dispersión general del poblamiento con relación a la fase anterior. Si en el S. III a.C. encontrábamos dos agrupaciones en las proximidades del Castell de Cocentaina y en la zona más alejada, en época final las distancias muestran una mayor gradación, sin concentraciones tan marcadas.

Por último, debemos referirnos al aumento en época final de las distancias medias de localización de los núcleos rurales con respecto al oppidum. Los doce núcleos rurales del s. III a.C. se localizaban a una media de $2512 \mathrm{~m}$ de distancia del Castell de Cocentaina y en época final se incrementa hasta los $3940 \mathrm{~m}$ de media en que se sitúan los 15 núcleos dependientes, un incremento de la distancia de 56,8 \%.

La tendencia del periodo es, por tanto, el alejamiento progresivo del poblamiento rural respecto al núcleo rector, generándose una distribución más dispersa que la del periodo anterior. Los cambios en la localización del poblamiento se traducen en una transformación de la estructura visual, es por ello que adquiere importancia el análisis comparativo de visibilidad acumulada que nos permita explorar estas transformaciones.

Los análisis de visibilidad mediante los SIG se fundamentan en la capacidad de calcular la intervisibilidad de dos puntos en el modelo digital del terreno del área de estudio. A partir de estos cálculos básicos se pueden extender las aplicaciones y proceder al tratamiento estadístico, la comparación o la cuantificación de dicha información ${ }^{6}$.

Una vez que se dispone del modelo digital de terreno que refleja las características topográficas del área de estudio, deben fijarse los factores determinantes de la cuenca visual a establecer, es decir las alturas del punto de observación, del punto observado y el diámetro límite del área visual. Por lo que respecta a la altura de los puntos observados y de observación hemos seleccionado $1,7 \mathrm{~m}$. que coincidirian básicamente con la altura del cuerpo humano y la posición del ojo humano con relación al nivel de base del terreno. Hemos declinado suponer que la observación pudiera realizarse desde un elemento construido como un lienzo de muralla o un torreón, ya que estos elementos serían inexistentes en la mayor parte de los asentamientos rurales en los que fijamos el punto de observación.
En segundo lugar debe fijarse la distancia que ha de limitar el cálculo de la cuenca visual. La mayor parte de los estudios de visibilidad convienen en señalar que la capacidad visual está limitada por la distancia, toda vez que la claridad y el contraste que permite el reconocimiento visual decrece en función de la separación entre el observante y el punto observado. De ello se deduce que hay que restringir el cálculo informático de la cuenca visual que produce el SIG a los valores previamente establecidos en nuestra investigación. Generalmente se ha propuesto la división de visibilidad en varios rangos a partir de las cualidades que se pueden percibir en función de la proximidad-distancia (Burillo et al., 1993). De forma similar, recientes análisis SIG han fundamentado la descomposición de la componente visual a partir de los parámetros establecidos por el paisajista japonés T. Higuchi, quien fijaba tres rangos, la corta, la media y la larga distancia para examinar de forma cuantitativa la relación entre el observante y los objetos de su campo de visión ${ }^{7}$. Los elementos en los rangos más cercanos permitirian la percepción visual de la mayor parte de las características del entorno, mientras que en la larga distancia únicamente se podrían percibir elementos aunque no son claramente identificables. En nuestro análisis proponemos una distancia límite de $3.300 \mathrm{~m}$ que permite la identificación de los elementos del entorno próximo y los asentamientos vecinos, según se desprende de las observaciones realizadas en el trabajo de campo. Esta distancia se situaría en el valor central del rango medio de Higuchi.

Una vez establecidos los parámetros para la realización de las cuencas visuales individuales, hemos procedido a sumar los resultados para conseguir el mapa con la visibilidad acumulada que nos indica cuántos asentamientos perciben cada punto del territorio (Fig. 7, 1 y 2). Puesto que nuestro interés resi-

\footnotetext{
${ }^{6}$ Remitimos al trabajo de P. Van Leusen 1998: Line-of sight and Cost Surface Analysis using GIS, en el que exponen los principios básicos y las limitaciones de las técnicas SIG para el estudio de la visibilidad. Véase el trabajo de M. Llobera (2003) para conocer los procedimientos SIG más complejos para el tratamiento de la visibilidad arqueológica.

${ }^{7}$ La distancia corta se extiende hasta los $360 \mathrm{~m}$, la distancia media hasta $6.600 \mathrm{~m}$ y a partir de esta distancia y hasta un limite de $18 \mathrm{~km}$ se extiende la larga distancia. Higuchi, T. 1983: Visual and spatial structure of landscapes. Massachussets. Véase la descripción detallada de estos principios y la aplicación a la visibilidad arqueológica en Wheatley y Gillings 2000, 17-19.
} 
de en la comparación de los resultados de épocas distintas, hemos procedido a reclasificar los resultados en un nuevo mapa que contemple valores porcentuales que puedan ser cotejados. Las áreas de magnitud visual baja se refieren a la porción de terreno controlado por menos del $33 \%$ de los asentamientos; la magnitud media se refiere a los sectores que se dominan visualmente por un porcentaje de asentamientos entre el 33 y el $66 \%$. Por último, las zonas controladas por más del $66 \%$ de los asentamientos han sido reclasificadas como zonas de magnitud alta.

La estructura visual del territorio en el s. III a.C. se corresponde con la agrupación del poblamiento en el entorno del oppidum, en el sector meridional del valle (Fig. 8, C). Los valores de mayor magnitud visual aparecen de forma muy compacta junto al poblado de altura, sin apenas bloques extendidos del conjunto principal y se sitúan en torno a ambas orillas del río Serpis. El sector de mayor magnitud visual es la orilla derecha, en los campos de cultivo que se localizan en el entorno de El Terratge y El Sompo. La orilla izquierda, donde se localiza el mayor número de asentamientos, muestra un índice semejante de visibilidad que se proyecta hacia las faldas de la sierra en un fenómeno propio de prominencia visual de los relieves destacados del entorno.

La mayor parte de los poblados se sitúan en zonas de alta y media magnitud visual, en concreto el $68 \%$, de lo que se desprende que existe una intensa comunicación intervisual entre los poblados próximos. Ello favoreceria la interacción social y la defensa del sistema de poblados (Fig. 9).

Los cambios que se producen en época final son tan evidentes como los apreciados en la distribución del poblamiento y se producen a consecuencia de dicha dispersión. El primer factor a destacar es la desaparición de una zona de intensa visibilidad en el entorno del oppidum de Cocentaina fruto del desplazamiento del poblamiento hacia las áreas septentrionales del valle, que en estos momentos concentrarán los mayores indices de magnitud visual (Fig. 8, D).

Además del desplazamiento hacia el norte se advierte una fragmentación de las zonas de mayor visibilidad. El sector de alta magnitud visual se encuentra fragmentado en tres pequeñas porciones que se distribuyen paralelas al cauce del rio, posiblemente en una morfología condicionada por el perfil topográfico de la zona. Por su parte, las zonas de magnitud visual media se muestran menos compac- tas y aparecen sectores desprendidos del conjunto principal, desde pequeñas islas hasta un gran sector, que se sitúan en la falda de la sierra del Benicadell, en el extremo norte, debido a la prominencia natural del relieve montañoso.

Los cambios son especialmente significativos en lo que respecta a la localización de los poblados con relación a las áreas de magnitud visual. La mayor parte de los asentamientos se sitúan en áreas de baja visibilidad, $62 \%$, siendo especialmente significativo que ninguno de ellos se localiza en áreas de alta magnitud visual (Fig. 9). Parece claro que se ha producido un ruptura del patrón visual de época plena que favorecía la cohesión en torno al oppidum, el control y la interacción visual entre la comunidad del valle.

\section{LA TRANSFORMACIÓN DE LAS ESTRUC- TURAS TERRITORIALES EN ÉPOCA IBÉRI- CA FINAL}

Según nuestra perspectiva, la época ibérica final es un periodo de complejos procesos que estarán marcados por la disolución de las estructuras vigentes en el periodo clásico, dinámica que en buena parte pudo originarse en el seno de las propias comunidades ibéricas y tendría sus manifestaciones en las formas de organización del territorio. De esta forma, las poblaciones modificarían sus tramas de poblamiento en el marco de las nuevas circunstancia que impondría el dominio de Roma.

En líneas precedentes hemos analizado varios componentes que permiten aproximarnos a la estructura del territorio. Por una parte hemos examinado las modificaciones del patrón de asentamiento que traslucen los cambios en las relaciones verticales que se producen en el seno de la sociedad ibérica, toda vez que el patrón jerarquizado de poblamiento nos remite directamente a la estratificación de la sociedad. Este primer examen nos ha permitido distinguir dos modelos claramente diferentes, el del territorio de la Serreta, que modifica drásticamente el patrón de asentamiento, y el de Cocentaina, que en principio mostraría la pervivencia del esquema de poblamiento. En segundo lugar, se ha profundizado en la distribución del poblamiento y la estructura visual del territorio de Cocentaina para examinar la aparente continuidad. Este segundo aspecto nos permite observar las relaciones territoriales de carácter horizontal, vinculadas a la proxi- 

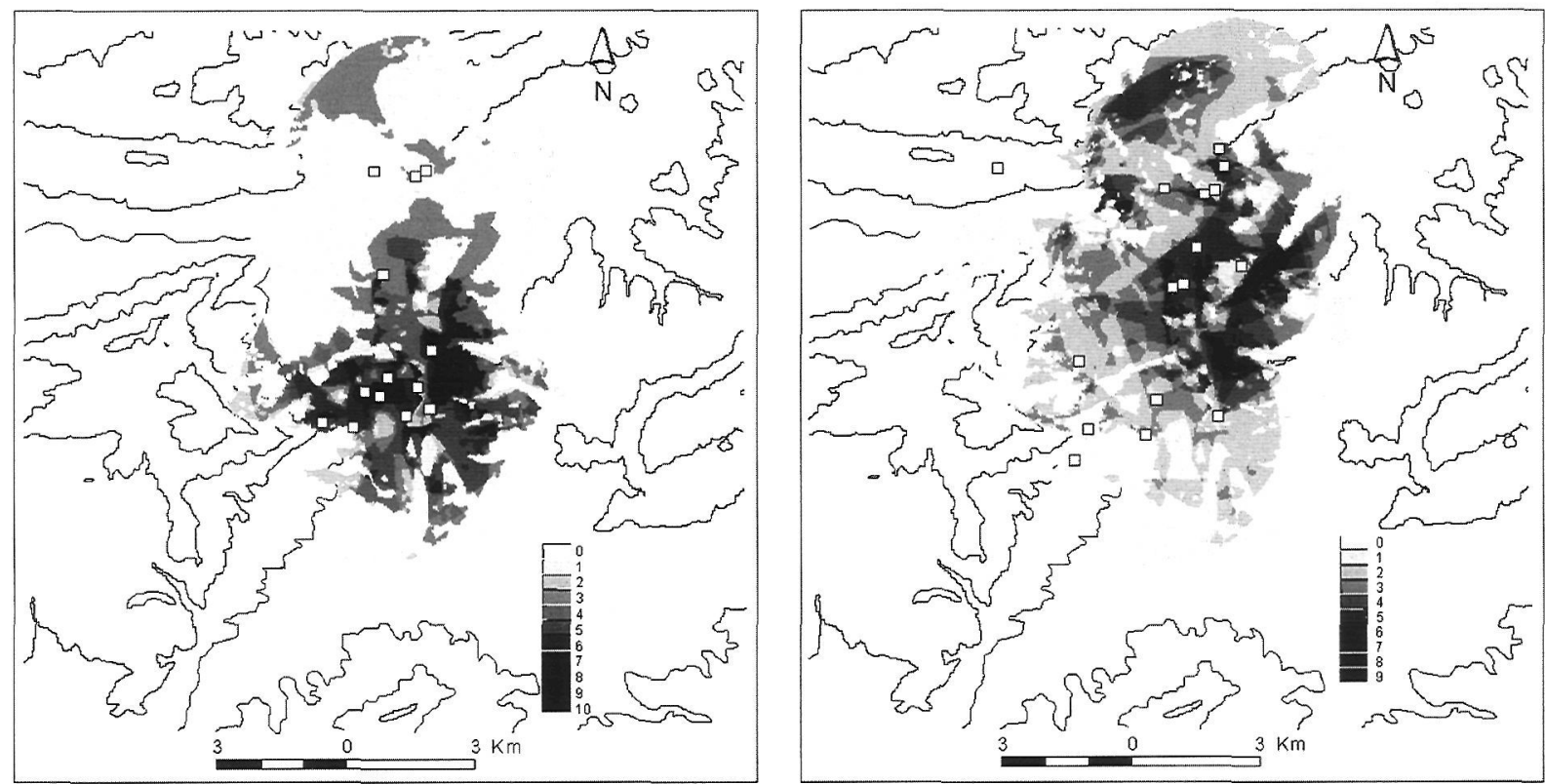

A
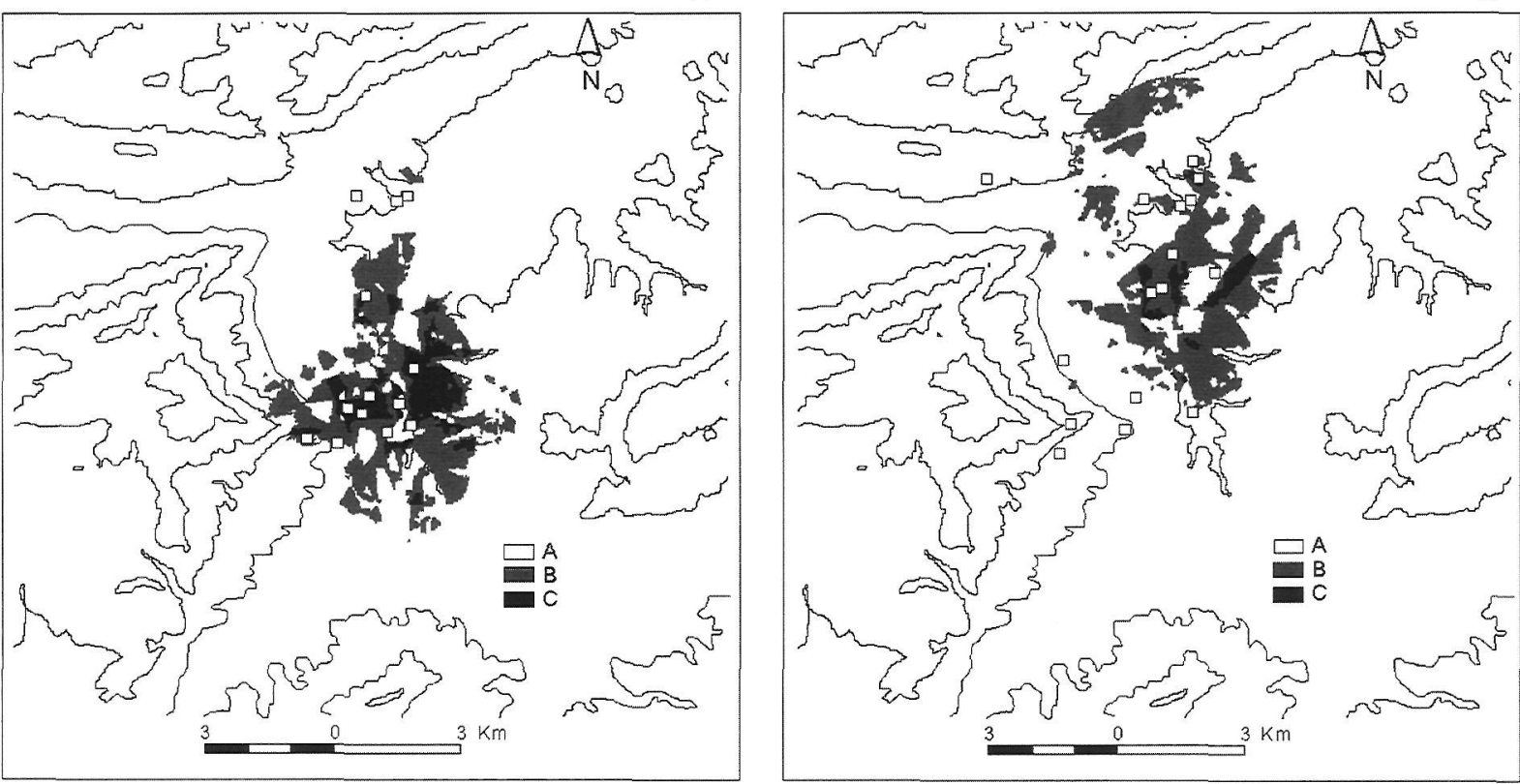

C

Figura 8: Visibilidad acumulada en el territorio de Cocentaina. A: Visibilidad Acumulada de época ibérica plena: número total de asentamientos. B: Visibilidad Acumulada de época ibérica final: número total de asentamientos. C: Visibilidad Acumulada de época ibérica plena: Magnitud visual: A: Alta; B: Media; C: Baja. D: Visibilidad Acumulada de época ibérica final: Magnitud visual: A.: Alta; B: Media; C: Baja.

midad entre el centro de poder y los núcleos dependientes.

Los procesos descritos muestran la desaparición de los grupos dirigentes de La Serreta, mientras que debieron mantenerse en los restantes oppida. Posiblemente la desarticulación del grupo dirigente de La Serreta se produjo como consecuencia de su función rectora de la amplia región del valle de Alcoi, no por su papel en el control de su territorio inmediato, aunque trajo como consecuencia la descomposición de este entorno. Por otra parte, todo parece indicar que se mantuvieron las estructuras encargadas de la gestión directa de cada uno de los pequeños valles. Sin embargo, el modelo de poblamiento no reprodujo de forma fiel las estructuras territoriales heredadas de época clásica, pues aunque preservó un patrón 


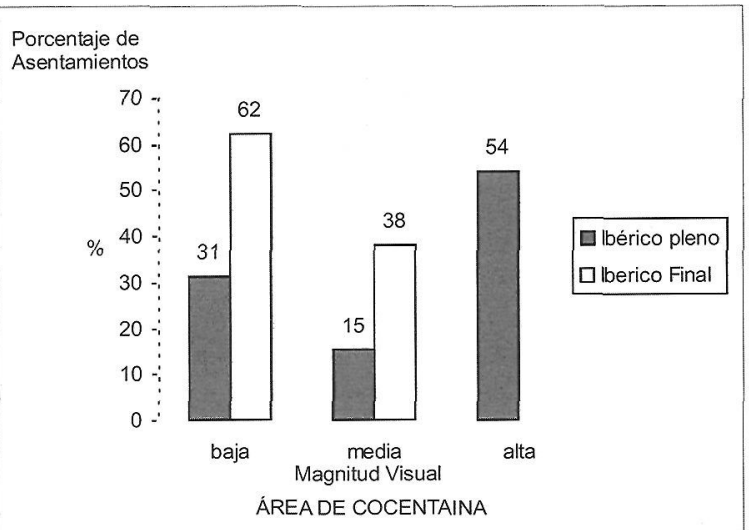

Figura 9: Porcentaje de asentamientos en el territorio de Cocentaina que se sitúan en cada una de las zonas de magnitud visual.

de asentamiento semejante, las relaciones horizontales reflejadas en la distribución del poblamiento y en la estructura visual muestran cambios significativos.

A lo largo del s. II-I a.C. se produjo un desarrollo del poblamiento rural que permite suponer un aumento de la proporción de la población dispersa con relación a la que se concentró en el poblado principal. Al mismo tiempo, los asentamientos dispersos se situaron más alejados del oppidum. Por último, se desintegró el foco de elevada magnitud visual en las proximidades del enclave rector. Todo ello nos lleva a proponer que los cambios son más profundos de lo que parece indicar la pervivencia del patrón de asentamiento de carácter jerarquizado. Durante los siglos del ibérico final se desgranó el modelo social ibérico representado por el oppidum con sus funciones y símbolos. Su pervivencia pudo deberse a la concentración de determinadas funciones, como la distribución comercial o la captación de tasas y tributos, pero posiblemente fueron disminuyendo las prioridades sociales que motivaban el protagonismo del oppidum y declinaría su función estrategia como refugio de la población campesina, pues el nuevo contexto de dominación romana debió imponer ciertas garantías de seguridad en los territorios. El nuevo sistema permitió el desarrollo de un poblamiento disperso que no se constreñía a las proximidades del oppidum, sino que se expandió por las tierras de cultivo más alejadas, produciendo una ampliación del paisaje agrario y consecuentemente de la producción agrícola. Quizás esta expansión agrícola se debió a la necesidad de ampliar los excedentes para satisfacer tributos impuestos por el nuevo dominador.
A nuestro parecer, la pervivencia del oppidum con su importancia menguada puede representar la continuidad y el cambio que subyace al proceso de romanización. La gestión directa del territorio se mantuvo en manos ibéricas, pero quizás bajo limitaciones y mediatizada por el control a distancia establecido por Roma. Una prueba de esta política la podemos encontrar en la desaparición del principal enclave urbano, La Serreta, tras la llegada de los romanos. Esta decisión muestra la voluntad de descapitalizar el territorio, quizá por las circunstancias propias del enfrentamiento bélico, y la resolución de no reemplazarlo por un enclave semejante presumiblemente mostraría el interés romano en evitar la existencia de un verdadero poder centralizado ibérico en la zona. De esa forma, los restantes oppida debieron pervivir con funciones limitadas, tratándose de evitar fuertes concentraciones de poder en manos de una elite ibérica que en el pasado se habría mostrado desafecta a los intereses romanos.

Las restricciones en las formas urbanas de la zona durante el periodo ibérico final pudieron estar en el origen de la ruralización de la comarca en época romana. En tiempos de Augusto, cuando se produjo el importante proceso de urbanización de la región contestana, los polos de poblamiento romanos se crearon a partir de los núcleos ibéricos precedentes o se articularon en zonas densamente pobladas en los principales corredores de comunicaciones (Grau Mira, 2000). Los valles de Alcoi no contaban en ese momento ni con entidades urbanas, ni con un entorno que pudiese propiciar las comunicaciones rápidas y fluidas. Estas carencias en la estructura sociopolítica y las limitaciones de su entorno físico debieron condicionar la inexistencia de núcleos urbanos en la zona. Como resultado de este proceso, no se articuló una estructura que amparara las nuevas relaciones sociales y que pudiera servir de base a la ciudad romana y sus funciones. La debilidad de las estructuras sociopolíticas, unida a las dificultades del medio físico, derivaria en la constitución de un entorno sin ciudades.

\section{VALORACIÓN FINAL}

En las páginas precedentes hemos tratado de explorar las transformaciones del poblamiento y del territorio producidas durante el periodo de romanización, especialmente los 
análisis de visibilidad mediante técnicas SIG. Pese a que los procedimientos de análisis visual han alcanzado un considerable desarrollo en el ámbito anglosajón, aun son escasas las aplicaciones en la arqueología española que trasciendan el marco del mero análisis binario de visibilidad-invisibilidad, como lo son en general las aplicaciones SIG en arqueología. Por ello hemos querido presentar esta metodología con su aplicación a un caso de estudio concreto, pues consideramos que las herramientas SIG ofrecen amplias posibilidades para explorar procesos espaciales y contrastar las hipótesis histórico-arqueológicas acerca de la estructura del territorio antiguo.

Generalmente los estudios de visibilidad en paisajes antiguos se han desarrollado en contextos relacionados con la construcción del paisaje simbólico, principalmente a partir de aproximaciones fenomenológicas relacionadas con la percepción visual de monumentos o elementos destacados del paisaje, como los megalitos o paneles de arte rupestre ${ }^{8}$. Sin embargo, hay que tener en cuenta que todo comportamiento cultural tiene una representación espacial, de forma que todos los paisajes poseen aspectos simbólicos con códigos propios; valga como ejemplo la centuriación romana que además de su propio aspecto funcional, representa la capacidad de planificación de un poderoso aparato estatal (Witcher, 1999, 16).

En las líneas precedentes hemos tratado de explorar la representación del poder ibérico en función de la proximidad al oppidum de los poblados dependientes, bien en distancia cartesiana, bien a partir del análisis de su estructura visual inherente a la distribución de asentamientos en un marco físico. Estos elementos muestran una dinámica de continuidad de las estructuras indígenas expresadas en el mantenimiento del oppidum y los patrones de asentamiento jerarquizados, pero al mismo tiempo se reconoce el germen de la disolución del modelo y el avance hacia formas dispersas de poblamiento.

Las pautas que se pueden establecer en la evolución de los territorios son un aspecto que añadir a los cambios que se reconocen en las vajillas cerámicas, las transformaciones urbanísticas, las pautas comerciales y tantos otros aspectos de la cultura material (Abad, 2003). Todos estos elementos contribuyen a construir una imagen más completa y detallada de los procesos dinámicos propios de la romanización.
Prof. Ignacio Grau Mira

Area de Arqueología

Dpto. de Prehistoria, Arqueología, $\mathrm{H}^{\mathrm{a}}$ Antigua,

Filología Griega y Filología Latina

Facultad de Filosofía y Letras

Universidad de Alicante

Apdo. 99

03080 Alicante

nacho.grau@ua.es

\section{BIBLIOGRAFÍA}

ABAD CASAL, L. 1984: "Romanización", Alcoi. Prehistoria y Arqueología. Cien años de investigación, 259-276, Alcoi.

ABAD CASAL, L. 1985: "La arqueologia romana del País Valenciano: panorama y perspectivas", Arqueología del Pais Valenciano. Panorama y perspectivas, 337-382, Alicante.

ABAD CASAL, L. 1987: "El poblamiento ibérico en la provincia de Alicante", en Ruiz, A. y Molinos, M. (Eds.): Iberos. Actas de las Primeras Jornadas sobre el Mundo Ibérico (Jaén, 1985), 159-169, Jaén.

ABAD CASAL, L. (Ed.) 2003: De Iberia in Hispaniam: la adaptación de las sociedades ibéricas a los modelos romanos, Madrid-Alicante.

BAENA, J., BLASCO, C. y QUESADA, F. (Eds.) 1997: Los S.I.G. y el análisis espacial en Arqueologia, Madrid.

BLÁZQUEZ J. M. y ALVAR, J. (Eds.) 1996: La romanización en occidente, Madrid.

BONET, H. y MATA, C. 2002: El Puntal dels Llops. Un fortín edetano, Trabajos Varios del SIP. 99, Valencia.

BURILLO, F., IBANÉZ, J. y POLO, C. 1993: Localización y descripción física del yacimiento y su entorno, Cuadernos del Instituto Aragonés de Arqueología, II, Teruel.

CLARKE, D.L. 1977: Spatial Archaelogy, London. (Traducción en español Arqueologia Espacial, 1984, Barcelona).

CHERRY, J. 1987: "Power in space: studies of the state", en Wagstaff, J. M. (Ed.): Landscape and Culture: Geographical and Archaeological perspectives, 146-72, Oxford.

CRIADO BOADO, F. 1993: "Visibilidad e interpretación del registro arqueológico", Trabajos de Prehistoria, 50, 3956.

CRIADO BOADO, F. 1999: Del terreno al espacio. Planteamientos y perspectivas para la Arqueología del Paisaje, CAPA, 6, Santiago de Compostela.

ESPI PÉREZ, I. 2001: "Noves dades sobre poblament ibèric i romà a les comarqeus de l'Alcoià i el Comtat. Les valls de les Puntes, Polop, Serpis mitjà i Alcalà", Recerques del Museu d'Alcoi, 10, 83-110

GONZÁLEZ VILLAESCUSA, R. 2001: El mundo funerario romano en el Pais Valenciano. Monumentos funerarios y sepulturas entre los siglos / a. de C.-VII d. de C, MadridAlicante.

GRAU MIRA, I. 1996: "La Romanización", en Historia de L'Alcoià, el Comtat y la Foia de Castalla, vol. I, 145-156, Alicante,

GRAU MIRA, I. 2000: "Continuidad y cambio en la trama urbana del Conventus Carthaginensis durante el proceso de romanización", Anales de la Universidad de Murcia, $n^{\circ} 16,33-51$.

\footnotetext{
${ }^{8}$ Véase el trabajo de $\mathrm{S}$. Fairén precisamente en éste mismo número de la revista $L$ ucentum que revisa las aproximaciones al tema.
} 
GRAU MIRA, I. 2001: "El jaciment de l'Arsenal i el poblament romà als entorns d'Alcoi", Recerques del Museu d'Alcoi, 10, 111-124.

GRAU MIRA, I. 2002a: La organización del territorio en el àrea centra/ de la Contestania lbérica, Alicante.

GRAU MIRA, 1. 2002b: "GIS approach to Iberian Iron age Landscape in Central-South Valencia region»,en Burenhurt, G. (Ed.): Pushing the envelope. Proceddings of the 2001. Computer Applications in Archaeology, 43-47, Oxford.

GRAU MIRA, I. 2003: "La reorganización del territorio durante la romanización: un caso de estudio en el área central de la Contestania", en Abad, L. (Ed.): De lberiam in Hispaniam. Las transformaciones de las estructuras indigenas durante la romanización, 51-71, MadridAlicante.

GRAU MIRA, I. y MOLTÓ GISBERT, S. 1996: "Hallazgo de una inscripción funeraria romana en Benicapsell (Planes. El Comtat)", Recerques del Museu d'Alcoi, 5, 209-212.

GUÉRIN, P. 1999: "Hogueras, molinos, telares... El Castellet de Bernabé y sus ocupantes", Arqueología Espacial, 21, 85-99.

GUÉRIN, P. 2003. El Castellet de Bernabé y el horizonte Ibérico Pleno edetano, Trabajos Varios del S.I.P., 101, Valencia.

HAGGETT, P. 1965: Locational Analysis in Human Geography, London.

HODDER, I. y ORTON, C. 1976: Spatial Analysis in Archaeology, Cambridge. (Análisis espacial en arqueología, Barcelona, 1990)

HIGUCHI, T. 1983: Visual and spatial structure of landscapes, Massachussets.

KEAY, S. J. 2001: “The romanization of Hispaniae", en Keay, S. J. y Terrenato, N. (Eds): Italy and the West. Comparative issues in Romanization, Oxford.

KEAY, S. y TERRENATO, N. 2001 (Eds.) Italy and the West. Comparative issues in Romanization, Oxford.

KEAY, S. J., WHEATLEY, D. y POPPY, S.. 2001: "The territory of Carmona during the turdetanian and roman periods: preliminary notes about visibility and urban location", en Caballos Rufino, A. (Ed.): Carmona Romana. Actas delll Congreso de Historia de Carmona, 397-412, Univ. de Sevilla y Ayto. Carmona.

LOCK, G. R., y HARRIS, T.M. 1996: "Danebury revisited: An English Iron Age hillfort in a digital landscape”, en Aldenderfer, M., y Maschner, H.D.G. (eds.): Anthropology, Space and Geographic Information Systems, 214-240, New York.

LLOBERA, M. 2003: "Extending GIS based analysis: the concept of visualscape", International Journal of Geographic Information Science, 1 (17), 25-48.

LLOBREGAT, E. 1972: Contestania Ibérica, Alicante.

LLOBREGAT, E. 1984: “Iberización”, Alcoi. Prehistoria y Arqueología. Cien años de investigación, 231-258, Alcoi.

LLOBREGAT CONESA, E.A., CORTELL PÉREZ, E., JUAN MOLTÓ, J., OLCINA DOMENECH, M. Y SEGURA MARTÍ, J.M. 1995: "El sistema defensiu de la porta d'entrada del poblat ibèric de La Serreta. Estudi preliminar", Recerques del Museu d'Alcoi, 4, 135-162.

MARTÍ BONAFÉ, M.A. y MATA PARREÑO, C. 1992: "Cerámicas de tipo fenicio occidental en las comarcas de L'Alcoià y El Comtat (Alacant)", Saguntum-PLAV, 25, 103117.

MAYER, M., NOLLA, J M. y PARDO, J. 1998 (Eds.): De les estructures indigenes a l'organització provincial romana de la Hispania Citerior, Barcelona.

MORATALLA, J. e.p.: «El territorio meridional de la
Contestania", en Jornadas de Arqueologia "La Contestania Ibérica, treinta años después", Alicante.

OLCINA DOMENECH, M., GRAU MIRA, I., MOLTÓ GISBERT, S., REIG SEGUII, C., SALA SELLÉS, F. y J.M. SEGURA MARTI .1998: "Nuevas aportaciones a la evolución de la ciudad ibérica: el caso de La Serreta", Congreso Internacional Los Iberos, Principes de Occidente (Barcelona, marzo 1998), 35-46, Barcelona.

OLCINA DOMENECH, M., GRAU MIRA, I., MOLTO GISBERT, S. 2000: "El sector I de la Serreta: noves perspectives al voltant de l'ocupació de l'assentament", Recerques del Museu d'Alcoi, 9, 119-144.

RUIZ, A. y MOLINOS, M. 1993: Los iberos. Análisis arqueológico de un proceso histórico, Barcelona.

RUIZ, A., MOLINOS, M., GUTIÉRREZ, L. M. y BELLÓN, J. P. 2001: “El modelo político del pago en el Alto Guadalquivir (S. IV-III a.n.e.)", Territori politic i territori rural durant I'Edat del Ferro a la Mediterrània Occidental. Actes de la Taula Rodona celebrada a Ullastret, Monografies d'Ullastret, 2 , 11-22.

SANDE LEMOS, F., BAENA, J., DANTAS GIESTAS, C. y ROCHA, G. (Coords.) 2000: Sistemas de Informação Arqueológica. S/G's aplicados à Arqueologia da Península Ibérica. Actas do $3^{\circ}$ Congresso de Arqueologia Peninsular. vol. $X$, Porto.

TARRADELL, M. 1988: "Prehistòria i Antiguitat", Història del Pais Valencià, I, 29-223, Barcelona

VAN LEUSEN, P. 1999: "Line-of sight and cost surface analysis using GIS", en Barceló, J.A., Briz, I. y Vila, A. (Eds.): New Techniques for Old Times: Computer Applications in Archaeology, 1998, 215-223, Oxford.

VISEDO MOLTÓ, C. 1923: Excavaciones en el monte La Serreta, próximo a Alcoy, Memorias de la Junta Superior de Excavaciones Arqueológicas, 56, Madrid.

VISEDO MOLTÓ, C. 1959: Alcoy. Geología. Prehistoria, Alcoy.

V.AA. 1998: Arqueología Espacial, 19-20. Arqueología del Paisaje, Teruel.

VV.AA. 2000: Empúries, 52, Empúries.

WHEATLEY, D. 1995: «Cumulative viewshed analysis: a GISbased method for investigating intervisibility, and its archaeological application», en Lock, G. y Stancic, Z. (Eds.): Archaeology and Geographical Information Systems, 171-185, London.

WHEATLEY, D. 1996: "The use of GIS to understand regional variation in Neolithic Wessex", en Maschner, D.G. (Ed.): New Methods, Old Problems: Geographic Information Systems in Modern Archaeological Research, Southern Illinois University Press.

WHEATLEY, D. y GILLINGS, M. 2000: "Vision, perception and GIS: developing enriched approaches to the study of archaeological visibility", en Lock, G. (Ed.), Beyond the map. Archaeology and Spatial Technologies, 1-27, Amsterdam.

WHEATLEY, D. y GILLINGS, M. 2002: Spatial technology and archaeology. The archaeological applications of GIS, London y New York.

WITCHER, R.E. 1999: "GIS and Landscapes of Perception", en Gillings, M., Mattingly, D. y Van Dalen J. (Eds.): Geographical Information Systems and Landscape Archaeology, 13-22, Oxford.

ZAMORA MERCHÁN, M. 2002: "Computerised and Real Viewsheds. An example from the Valley of the Genil River, Southern Spain", Archaeological Computing Newsletter, $58,7-10$. 